\title{
General or regional anaesthesia for postpartum haemorrhage
}

\author{
Wikkelsø $\mathrm{AJ}^{1}$, Secher $E^{2}$, Edwards $H^{3}$.
}

${ }^{1}$ Department of Anaesthesia and Intensive Care Medicine, Herlev Hospital, Herlev, Denmark
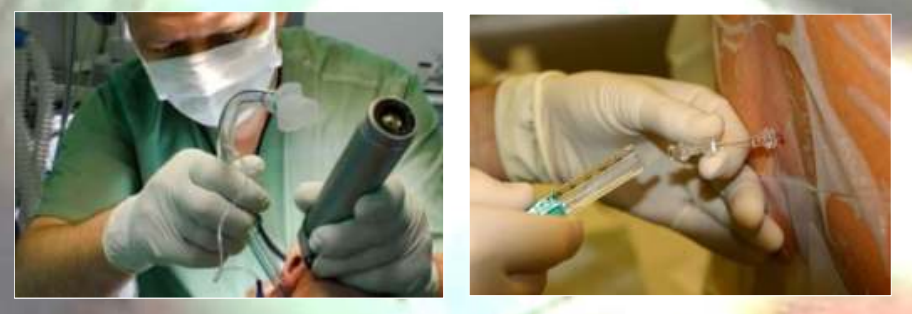

\section{Background and Goal of Study}

First line surgical treatment for postpartum haemorrhage (PPH) following vaginal delivery is manual emptying of the uterine cavity. Anaesthesia is provided as regional anaesthesia (spinal/epidural) or general anaesthesia. Method depends on airway risk assessment, circulatory instability due to haemorrhage, and local tradition. We aim to describe the Danish national variation in choice of anaesthesia for PPH. We hypothesized that small centres with few annual deliveries were more likely to choose general anaesthesia.

\section{Materials and Methods}

Using the National Danish Patient Register we defined our population by the SKS-procedure codes KMBA10,30,30A: manual removal of placenta, placental parts or manual exploration of the uterus due to continuous bleeding after placental delivery performed during 2010 to 2015 . The Danish Anaesthesia Database (DAD) contains information on mode of anaesthesia. A merge between the two registries was performed. Logistic regression was used $(p<0.001)$.

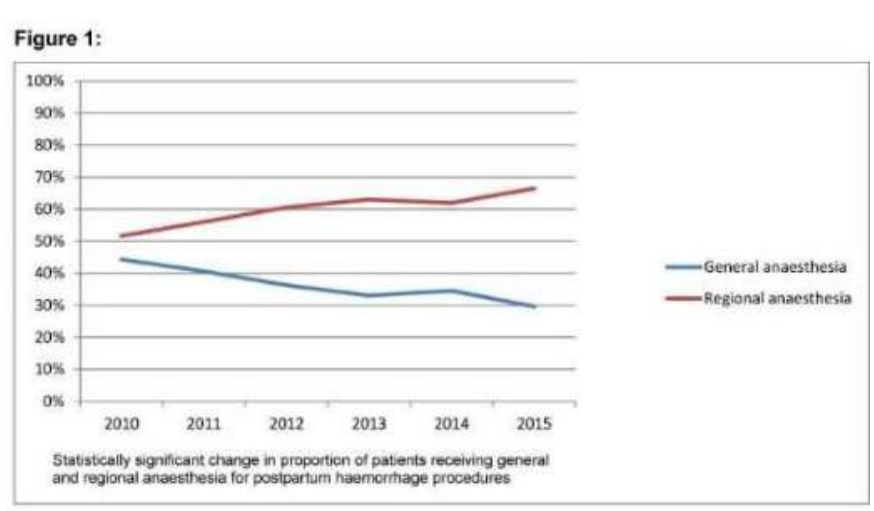

\section{Results}

Denmark had a total of $11,053 \mathrm{PPH}$ treatment procedures in 27 different centres complicating $3 \%$ of deliveries during 2010 to 2015. Three centres did not report to DAD and some centres did not report or exist during the entire period. Mode of anaesthesia was obtained for $5,750(52 \%)$ procedures. We found a significant increase in the use of regional anaesthesia during the period and a corresponding decrease in the use of general anaesthesia (Figure 1). Small centres had a significantly higher proportion of patients receiving general anaesthesia (Figure 2). Large centres had a significantly higher proportion receiving regional anaesthesia. We found no difference in the proportion of deliveries complicated by $\mathrm{PPH}$ treatment procedures between centres or during the period.

\section{Discussion}

Regional anaesthesia is increasingly being used in the treatment of PPH. This tendency follows the recommendation for caesarean section due to increased risk related to tracheal intubation. However, regional anaesthesia may cause circulatory collapse with severe haemorrhage. Thus, the higher proportion of patients receiving general anaesthesia in small centres could suggest that inexperience at the initial circulatory assessment prompts more patients to be given general anaesthesia.

\section{Conclusion}

Small delivery centres are more likely to choose general anaesthesia for PPH treatment procedures.

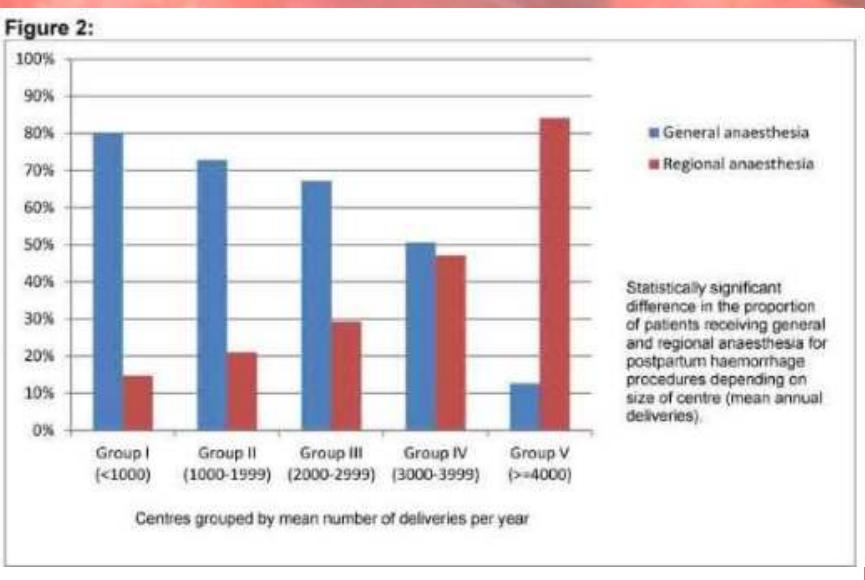

